Martijn A. Spruit ${ }^{1,2}$, Chris Burtin², Patrick De Boever ${ }^{3,4}$, Daniël Langer ${ }^{5}$, martijnspruit@ciro-horn.nl loannis Vogiatzis ${ }^{6}$, Emiel F.M. Wouters ${ }^{1,7}$, Frits M.E. Franssen ${ }^{1,7}$ [1]

'Dept of Research and Education, CIRO+, Center of Expertise for Chronic Organ Failure, Horn, The Netherlands. 2REVAL Rehabilitation Research Center, BIOMED Biomedical Research Institute, Faculty of Medicine and Life Sciences, Hasselt University, Diepenbeek, Belgium. ${ }^{3}$ Environmental Risk and Health, Flemish Institute for Technological Research (VITO), Mol, Belgium. ${ }^{4}$ Centre for Environmental Sciences, Hasselt University, Hasselt, Belgium. ${ }^{5}$ Faculty of Kinesiology and Rehabilitation Sciences and University Hospitals Leuven, Respiratory Rehabilitation and Respiratory Division, KU Leuven-University of Leuven, Leuven, Belgium. ${ }^{6} \mathrm{National}$ and Kapodistrian University of Athens, Faculty of Physical Education and Sports Sciences and 1st Dept of Respiratory Medicine, Athens, Greece. ${ }^{7}$ Dept of Respiratory Medicine, Maastricht University Medical Center (MUMC+), Maastricht, The Netherlands.

\section{COPD and exercise: does it make a difference?}

Exercise training is widely regarded as the cornerstone of pulmonary rehabilitation in patients with chronic obstructive pulmonary disease (COPD). Indeed, exercise training has been identified as the best available means of improving muscle function and exercise tolerance in patients with COPD. So, exercise training truly makes a difference in the life of patients with COPD. In this review, an overview is provided on the history of exercise training (as standalone intervention or as part of a comprehensive pulmonary rehabilitation programme), exercise training in comorbid patients with COPD, and the impact of physical activity counselling in a clean air environment.

@ERSpublications

Exercise training in COPD, as part of a comprehensive pulmonary rehabilitation programme, makes a profound difference http://ow.ly/wT9U300mbru

\section{Summary}

Physical activity is defined as any bodily movement produced by skeletal muscles which results in energy expenditure. Physical activity in daily life can be categorised into occupational, sports, conditioning, household, or other activities. Exercise is a subset of physical activity that is planned, structured, and repetitive and has as a final or an intermediate objective the improvement or maintenance of physical fitness [1]. According to international guidelines, exercise training, widely regarded as the cornerstone of pulmonary rehabilitation, is the best available means of improving muscle function and exercise tolerance in patients with chronic obstructive pulmonary disease (COPD) [2, 3]. It truly makes a difference in the life of patients with COPD. In this review, an overview is provided on the history of exercise training (as standalone intervention or as part of a comprehensive pulmonary rehabilitation programme), the state-of-the-art exercise training, exercise training in comorbid patients with COPD, and the impact of physical activity counselling in a clean air environment.

\section{The history of exercise-based pulmonary rehabilitation}

In 1894, Baron Pierre de Coubertin founded the International Olympic Committee (IOC). During the first IOC Congress (organised in Paris from June 16 to 23 1894), it was decided that the inaugural Olympic Games to come under the auspices of the IOC would take place in Athens in 1896 [4]. At the same time, Dr Denison, professor of Diseases of the Chest and of Climatology at University of Denver, published a book with the inspiring title "Exercise and food for pulmonary invalids", in which he emphasised the importance of physical exercise and healthy food for the health of "pulmonary invalids" [5]. This was
Cite as: Spruit MA, Burtin C, De Boever $\mathrm{P}$, et al. COPD and exercise: does it make a difference? Breathe 2016; 12 : $1-12$ 
most probably the first publication in which the use of exercise training as part of disease management of chronic lung disease was recommended.

More than 50 years later, in 1952, BARACH et al. [6] reported that enhancement in capacity to walk without breathlessness can result in a physiological response similar to a training programme in athletes. Indeed, in two patients with pulmonary emphysema in whom dyspnoea on exertion was relieved during inhalation of oxygen, an exercise programme was started with subsequent remarkable improvement of capacity to exercise without oxygen [6]. The same research group again recommended in 1964 the use of exercise training: "It may seem unusual perhaps to suggest exercise to these breathless people, but in fact it is one of the ways by which they can restore physical fitness." [7]. NoEHREN et al. [7] also suggested that physical inactivity may play an important role in the observed physical deconditioning: "I am unhappy about patients who always use an elevator to go up stairs" and "The muscles in the legs of these people are very often atrophied". Five years later, PETTY et al. [8] were the first to describe the effects of a comprehensive care programme for people with "chronic airway obstruction". The programme consisted of multidisciplinary baseline evaluation, followed by individual instructions for bronchial hygiene, breathing retraining, graded exercises (daily, for $1 \mathrm{~h}$ ), and even a home visit by the nurse. Finally, outcome evaluation took place during the programme, at the end of the programme and 1 year later. They reported positive effects on multiple outcomes, ranging from daily symptoms and exercise tolerance, up to a return to gainful employment and healthcare utilisation. The total number of hospital days ( $n=868)$, the number of hospitalised patients ( $n=34$, which equaled $22.4 \%$ of the total sample) and the mean length of stay ( 25 days) in the year before the programme were clearly higher compared with the first year of the programme $(n=542,25$ and 21.7, respectively) [8]. This was the first proof that a comprehensive care programme including graded exercise training improved healthcare utilisation in patients with "chronic airway obstruction".

In 1970, Bass et al. [9] were among the first to assess the true change in exercise performance in symptomatic COPD patients with dyspnoea either during walking at an ordinary pace on level ground or during washing or dressing and with the motivation to lead a more active life. After 18 weeks of a stationary cycle-based exercise training programme, patients with COPD improved their maximal work load by about $85 \%$ compared with baseline. In addition, $92 \%$ of the patients claimed that they could "do more" and reported an increase in daily physical activity [9]. Indeed, these authors pioneered a study to assess physical activity levels using a pedometer (unfortunately without any specification) and daily activities using a diary. Moreover, they were also the first to describe the negative impact of "acute bronchitis" on the level of physical activity [9]. Only 36 years later, PITTA et al. [10] objectified the decline in physical activity levels during an exacerbation-related hospitalisation, using a validated accelerometer.

In 1981, the first official ATS Statement on Pulmonary Rehabilitation was published, in which pulmonary rehabilitation was defined as "an art of medical practice wherein an individually tailored, multidisciplinary programme is formulated which through accurate diagnosis, therapy, emotional support and education, stabilises or reverses both the physio- and psychopathology of pulmonary diseases and attempts to return the patient to the highest possible capacity allowed by his pulmonary handicap and overall life situation" [11]. In 1992 [12], 1999 [13], 2006 [14] and 2013 [3] subsequent updates were published, keeping in line with the ongoing scientific developments. Exercise training was always identified as a cardinal component of pulmonary rehabilitation for patients with COPD.

Also in 1981, BeLman and Kendregan [15] published new data on the changes in quadriceps muscle structure following exercise training in patients with COPD. Five men and two women underwent 6-week lower limb cycle training, starting at approximately one-third of the maximum load reached in the incremental test. Despite a high compliance (mean attendance was 45 sessions out of the maximum 48 sessions), the improvement in exercise performance was only observed in about half of the patients. Moreover, activity of the oxidative enzymes citrate synthase, 3- $\beta$-hydroxyacyl CoA dehydrogenase and pyruvate kinase in the biopsy specimens of the quadriceps lateralis muscle did not change significantly compared with baseline [15]. So, the authors concluded that the improvements in exercise tolerance following exercise training were probably due to an increased motivation, desensitisation to dyspnoea, improved skills, or a combination thereof; but not due to true physiological changes at the level of the lower-limb muscles [15]. At first sight, the lack of improvement in muscle enzyme activity came as a surprise. Nevertheless, the training intensity was most probably too low to increase enzyme activity at all, which was also commented upon by others [16].

In 1991, CASABURI et al. [17] did report a reduction in exercise-induced lactate and ventilation at iso-time during a constant work rate cycling test following exercise-based pulmonary rehabilitation, in particular in COPD patients who performed their exercise training at high work rates. So, improvement in exercise performance following exercise training at moderate-to-high intensity was proposed to be related, at least in part, to physiological changes at the level of the lower-limb muscles. In 1996, Maltais et al. [18] did provide evidence that exercise training can result in physiological 


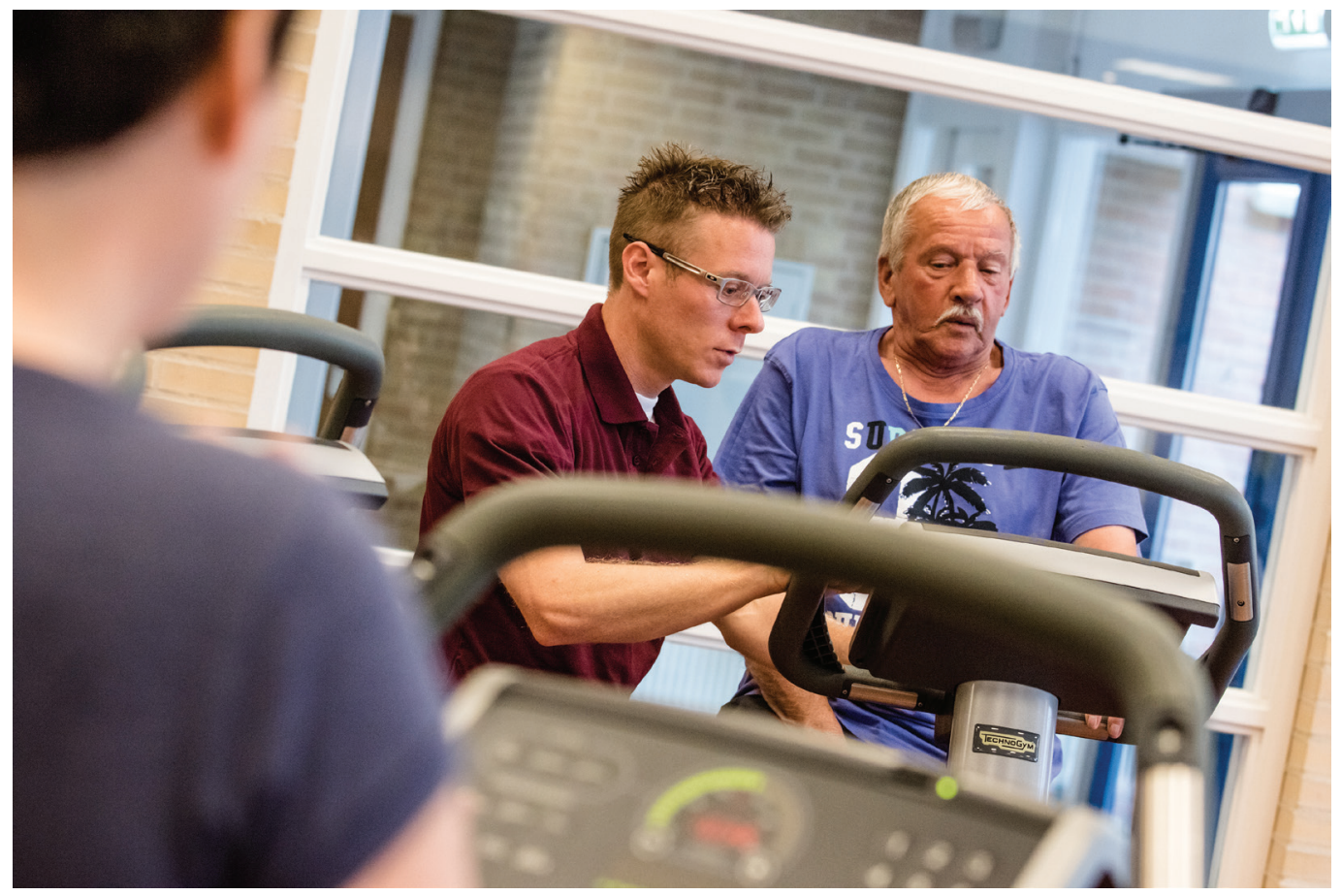

changes, including an increased oxidative enzyme activity (i.e., citrate synthase and 3-hydroxyacyl-CoA dehydrogenase) and a reduced exercise-induced lactate production, following a 12-week aerobic training programme in patients with COPD. This truly provided a strong scientific basis for exercise training as a cornerstone of pulmonary rehabilitation in patients with COPD. Indeed, RIEs et al. [19] already demonstrated in 1995 that exercise training in combination with education resulted in a significantly greater increase in exercise performance compared with education alone in 128 patients with COPD. These authors, however, did not assess the metabolic changes within the lower-limb muscles. So, whole-body endurance exercise training was the common standard for pulmonary rehabilitation in patients with COPD. In 1997, however, MALTAIS et al. [20] demonstrated that a majority of patients with COPD were unable to perform aerobic exercise at a high intensity. Therefore, other training modalities were introduced for patients with COPD, including interval training (which will be discussed in depth later in the article) [21].

In 1992, Simpson et al. [22] started with the evaluation of the efficacy of weightlifting exercises in patients with COPD. 34 patients were randomly assigned to 8 weeks of weightlifting or usual care. Training sessions were held three times a week for 8 weeks. Weight lifting consisted of 10 repetitions of single arm curl, single leg extension and single leg press exercise, which were repeated three times. The resistance was increased progressively from $50 \%$ of one repetition maximum during the first week to $85 \%$ during the final week of training. The one repetition maximum for all the exercises was re-evaluated every sixth session and adjusting the resistance in terms of the most recent maximum ensured a constant relative training stimulus. Subjects were coached and observed to obtain a slow smooth movement with normal breathing control during the lifting phase of the exercise. Resistance training significantly increased muscle strength, while no changes were observed in the usual care control group. Maximal incremental exercise capacity and 6-min walk distance did not change following the 8 weeks of resistance training. In contrast, mean $\pm S D$ endurance to fatigue during cycling at $80 \%$ of maximum exercise capacity improved significantly from $518 \pm 69 \mathrm{~s}$ to $898 \pm 95 \mathrm{~s}(\mathrm{p}<0.01)$, but was unaffected in the usual care control group. Also, the domains "dyspnoea", "fatigue" and "mastery" of the Chronic Respiratory Questionnaire improved significantly following resistance training. So, local muscle training improved lower-limb muscle function, exercise endurance and quality of life in patients with COPD [22]. Afterwards, multiple studies have confirmed the positive effects of resistance training in patients with COPD, as summarised by O'SHEA et al. [23]. Meanwhile, it is very well known that a lower metabolic cost of local muscle training results in a lower burden on the impaired ventilatory system compared with whole-body endurance training [24]. In turn, this type of training is especially suitable for COPD patients with low ventilatory reserve and severe dyspnoea. Besides resistance training, other training modalities have also been introduced over the past 15 years. Indeed, there are beneficial effects reported on lower-limb muscle function, exercise performance and quality of life in patients with COPD following neuromuscular electrical stimulation [25], water-based training [26], one-legged cycling [27], Tai Chi [28], Nordic walking [29], whole-body vibration [30] and non-linear exercise training [31]. 
To date, the most optimal format of exercise training (i.e., type, intensity, frequency and duration) for patients with COPD is still subject to investigation. Accordingly, the major issue of interest has been the selection of the appropriate training method that is tailored to the cardiovascular, pulmonary and peripheral muscle limitations of the individual patient so as to maximise the effect of exercise conditioning. Although high-intensity constant-load exercise is generally argued to be needed for an improvement in exercise capacity [31], ventilatory limited patients and those with profound muscle weakness are usually unable to sustain high exercise intensities for sufficiently long periods [19]. An alternative approach that allows high-intensity exercise to be performed for sufficiently long periods of time to achieve true physiological effects is interval exercise. This form of exercise comprises a sequence of on-and off-high intensity muscular loading events with tolerable levels of dyspnoea sensations [32]. In healthy trained individuals, application of interval exercise allows heavy loads to be imposed upon both peripheral muscles and oxygen-transporting organs without a profound engagement of anaerobic processes. This reduction in metabolic acidosis, allows a greater amount of work to be performed before exhaustion sets in [33].

The paradigm of sail pumping in Olympic-class windsurfing is representative of the advantages of interval exercise. Sail pumping is a highly demanding endurance manoeuvre in which the athlete rhythmically pulls a $9.5 \mathrm{~m}^{2}$ sail so that it acts as a wing, thus providing the board with additional forward motion in light and moderate wind conditions. Accordingly, in a typical regatta, lasting 30-45 min, metabolic acidosis is likely to present a limiting factor to muscle performance, especially in the relatively small but hard working muscles of the upper body [34]. This is the reason why Olympic-class windsurfers set pumping frequencies at or slightly above the exercise intensity that represents the lactate threshold.

The accessibility of portable gas exchange and lactate analysers has allowed exercise scientists to determine the lactate threshold of the individual sailor during sea training. Typically windsurfers alternate periods (15-30 s) of high- and lower-frequency pumping actions so as to maintain oxygen uptake and heart rate recordings to levels corresponding to their lactate threshold $[35,36]$. In patients with advanced COPD, interval exercise consisting of repeated bouts (30-60 s) of high- or even maximal-intensity work (80-100\% peak) separated by periods (30-60 s) of lower intensity work intervals, has been shown to be associated with a small increase in arterial lactate concentration, lower ventilation and degrees of dynamic hyperinflation and lower symptoms of dyspnoea and leg discomfort, thus allowing the total amount of work performed to be significantly greater than that of constant-load exercise [37].
Implementation of high-intensity interval training in patients with COPD has proven to be effective in terms of improvements in vastus lateralis capillarisation and muscle fibre oxidative capacity, thus enhancing the utilisation of oxygen by the exercising muscles [38]. Furthermore, this type of training is effective in reducing the magnitude of exercise-induced dynamic hyperinflation and associated dyspnoea sensations [39], as well as improving central haemodynamic responses [40] during exercise in patients with COPD.

\section{Exercise in comorbid patients with COPD}

Comorbidities, defined as the presence of one or more additional disorders co-occurring with COPD, are incorporated in the definition of the disease as it is recognised that they impact on the burden of disease in individual patients [41]. Comorbidities such as diabetes, hypertension and cardiovascular disease, increase the risk of hospitalisation [42] and mortality [43]. While smoking is an obvious risk factor for the development of other chronic diseases in COPD, the prevalence of several comorbidities, including coronary artery disease, hypertension, osteoporosis and anxiety, is higher in smokers than non-smokers [44]. This suggests that additional risk factors exist in COPD; low physical activity, systemic inflammation, accelerated ageing and poor diet probably contribute to the development of (specific) comorbidities in individual patients [45].

Most patients referred for pulmonary rehabilitation suffer from one or more comorbidities [46]; thus, it is important to consider their impact on the efficacy and safety of and patient compliance during an exercise-based pulmonary rehabilitation programme. Several studies have investigated the impact of individual comorbidities on outcomes of pulmonary rehabilitation [47]. The results of these studies are rather inconclusive; the majority of studies had a retrospective design, focused on different individual comorbidities and the diagnoses of comorbidities were mostly based on self-report or medical records. Moreover, it was recently shown that most comorbidities in patients referred for pulmonary rehabilitation remain undiagnosed and untreated [48], suggesting that clinicians and scientists should actively search for the impactful comorbidities. One of the few prospective studies was performed by CRISAFULLI et al. [49], including patients with moderate to severe COPD participating in a comprehensive outpatient pulmonary rehabilitation programme. Only the presence of osteoporosis was inversely related to improvement in functional exercise tolerance. Neither did the number of comorbidities affect the outcomes of exercise-based pulmonary rehabilitation, nor did the adherence to the programme differ across 


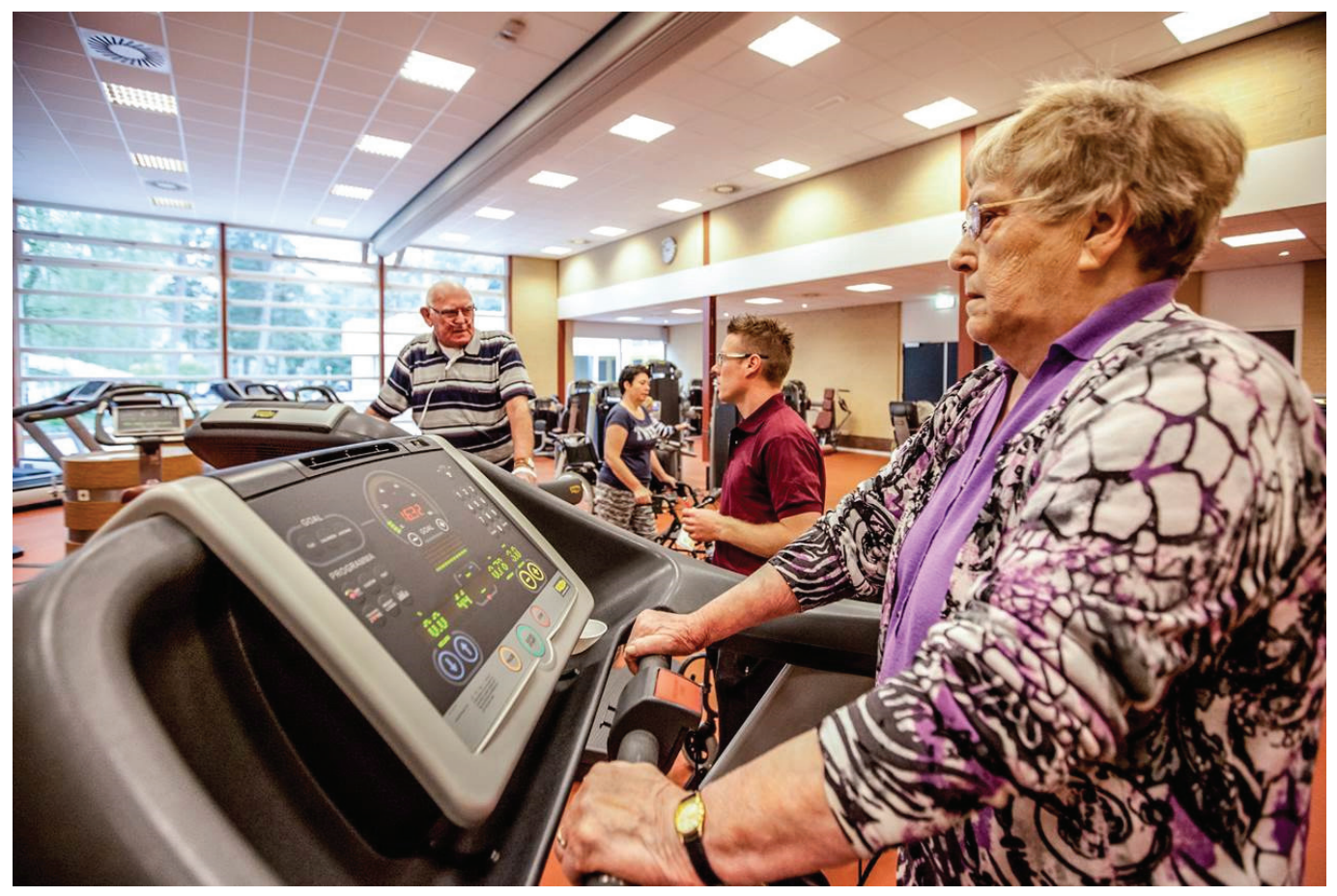

comorbidity categories [44]. Recently, MEsQuitA et al. [50] studied the impact of thirteen objectively identified comorbidities on pulmonary rehabilitation outcomes. None of the individual comorbidities changed the likelihood for a clinically meaningful change in exercise tolerance or health status. Also, the number of comorbidities did not affect the outcomes. These findings suggest that it is safe to for patients with COPD and comorbidities to obtain significant and clinically relevant improvements in functional exercise capacity and health status after a pulmonary rehabilitation programme. Obviously, diagnosis and adequate treatment of impactful comorbidities in patients referred for exercise-based pulmonary rehabilitation is important. Unstable central and peripheral cardiovascular disease, severely impaired cognitive functioning and serious musculoskeletal problems are among the few contra-indications for pulmonary rehabilitation and need to be addressed during pre-rehabilitation assessment [51]. Also, ongoing monitoring for symptoms and signs of unstable health during the course of pulmonary rehabilitation is warranted [47]. In addition to state-of-the art diagnostic tools and facilities, this requires specific expertise and an interdisciplinary approach from healthcare professionals involved in pulmonary rehabilitation. Additional studies are warranted to identify whether specific programme modifications for patients with co-occurring medical conditions will enhance the gains in various outcomes following pulmonary rehabilitation for patients with differing comorbidities.

Beneficial effects of exercise-based pulmonary rehabilitation on comorbidities have also been reported. Exercise-based pulmonary rehabilitation was significantly more effective in reducing shortterm anxiety and depression than standard care [52]. Reductions in pulse wave velocity, a marker of cardiovascular risk have also been reported after exercise-based pulmonary rehabilitation [53, 54], although a larger observational study did not confirm this [55]. This highlights the complex and heterogeneous pathophysiology of cardiovascular disease in COPD. Finally, the effects of nutritional supplementation and/or counselling and exercise training as a part of pulmonary rehabilitation on body weight, muscle mass and structural skeletal muscle abnormalities are well-recognised [56]. Recently, positive effects of a specific pulmonary rehabilitation programme aimed at obese COPD patients were reported for the first time [57].

\section{Exercise training as part of a comprehensive pulmonary rehabilitation programme}

Even though it has been difficult so far to quantify the added value of non-exercise components to the effectiveness of pulmonary rehabilitation, several of these interventions are frequently incorporated into these programmes and are considered to be clinically relevant $[58,59]$. These treatment strategies are frequently addressing psychosocial and lifestyle changes associated with chronic respiratory conditions with the aim of teaching patients how to better manage impairments and to reduce symptom burden. They have been designed to address a broad range of 
issues including treatments to facilitate smoking cessation, optimising pharmacotherapy, assisting with early identification and treatment of acute exacerbations, managing acute dyspnoea, increasing participation in physical activity, improving body composition, promoting mental health and establishing social support networks $[60,61]$. Treatments are offered by a dedicated, interdisciplinary team, including physicians, physiotherapists, respiratory therapists, nurses, psychologists, behavioural specialist, exercise physiologists, nutritionists, occupational therapists and social workers [3]. Education is considered an important component of comprehensive pulmonary rehabilitation and is integrated into virtually all programmes [59]. In addition to standard didactic sessions, education may also include instructions on how to incorporate breathing strategies, such as pursed-lip breathing into daily life. Also instructions on energy conservation and work simplification techniques can be included. In many programmes these educational components are embedded within an intervention provided by an occupational therapist. Dyspnoea is the most disabling symptom for people with COPD and is often the reason that medical attention is sought. Strategies that have been demonstrated to ameliorate dyspnoea, other than participating in supervised exercise training, include adopting a forward-leaning sitting position, pursed lip breathing and the use of a rollator (or four-wheeled walker) to assist with ambulation [62-64]. Together with inspiratory muscle training, these treatments are likely to reduce the sensation of unrewarded inspiration that is perceived as dyspnoea [64]. These strategies are useful to implement within the context of pulmonary rehabilitation, as people have the opportunity to utilise them both during periods of increased dyspnoea associated with supervised exercise training as well as during physical activities performed in daily life. Psychosocial and behavioural interventions in pulmonary rehabilitation may include educational sessions focusing on specific problems such as stress management, instructions in relaxation exercises, panic control, smoking cessation, assisting with early detection and treatment of acute exacerbations, and stimulating participation in regular physical activity [3]. Anxiety, depression and difficulties in coping with chronic disease are common in COPD patients and contribute to morbidity. Informal discussions during rehabilitation sessions of symptoms, concerns and problems common to COPD patients may be beneficial [3]. Individuals with major psychiatric conditions should be referred to appropriate professionals. Weight loss and muscle wasting, which are present in $20-35 \%$ of patients with stable COPD, contribute to morbidity and mortality in COPD, independent of the pulmonary physiological abnormality [65]. Nutritional interventions should be considered for these patients, especially while experiencing increased exercise-related energy expenditure during participation in the programme. There is also an increasing number of individuals with chronic respiratory diseases and coexisting obesity referred for pulmonary rehabilitation [3]. This specific group my benefit from targeted interventions in addition to exercise training, including nutritional education, restricted calorie meal planning, encouragement for weight loss and psychological support.

\section{Physical activity coaching}

Patients with COPD are markedly inactive in daily life, showing a decrease in the amount of time spent actively, a decreased intensity of activities and an increase of sedentary periods throughout the day [66]. Symptoms of breathlessness and fatigue during physical activities are associated with activity-avoiding behaviour which will in turn exacerbate the experienced symptoms due to deconditioning. In recent years, daily physical activity has become a key target for intervention trials aiming to improve long-term health status [67]. Indeed, physical activity levels play a key role in the onset of muscle dysfunction and deconditioning and have been associated with quality of life, hospital admission, comorbidities, lung function decline and mortality [67-71]. To date, evidence is lacking that an increase in physical activity following a specific intervention will reduce the burden of COPD. Only observational studies show that patients with COPD with a low level of physical activity or who reduced their physical activity over time are expected to experience a significant increase in hospitalisation and/ or mortality rate [71, 72].

Unfortunately, improvements in muscle function and exercise tolerance after pulmonary rehabilitation do not automatically translate into enhanced physical activity behaviour [73]. Inducing such a behavioural change seems to be more complex than simply improving physical capacity [74]. Along with socio-demographic and environmental factors, patients' health beliefs, perception of symptoms, self-efficacy and motivation are likely to impact on physical activity levels. Social support, the option to participate in group activities, the perceived benefit and the availability of professional support are frequently reported as enablers of physical activity behaviour [75, 76]. The importance of these aspects varies among individuals.

Now, it is clear that a more individually tailored and comprehensive intervention is warranted to effectively target human behaviour. The recent official European Respiratory Society Statement on Physical Activity in COPD summarises the key components that increase the effectiveness of behavioural interventions that include mobilising 
social support, using well-described/established behaviour change and self-regulatory techniques (i.e., self-monitoring, stimulus control, problem solving, relapse prevention management, goal setting, self-reinforcement, providing feedback on performance and developing action plans), providing higher contact time or contact frequency, and assessing the readiness and motivation to change [67].

Principles of motivational interviewing have been used to obtain lifestyle changes in several health behaviours including smoking, dietary habits, substance abuse and physical activity. In terms of physical activity behaviour, this patient-centered approach focuses on the identification of personal barriers and enablers towards daily physical activity and stimulates the patients to actively search for solutions to overcome existing barriers. Enhancing motivation and self-efficacy to impact on physical activity behaviour is key in the process. In COPD, the addition of an individually tailored activity counselling programme, using motivational interviewing and goal setting strategies, on top of a pulmonary rehabilitation programme failed to increase physical activity levels [77].

Direct feedback from a pedometer or an activity monitor seems to be an important tool to optimise the success rate of physical activity counselling programmes [78]. Several trials have reported a marked increase in physical activity after counselling interventions using real-time activity feedback, both as a stand-alone intervention and on top of pulmonary rehabilitation [79-81]. Mobile phone applications might play an important role during these interventions in the future [80]. This type of approach challenges patients with COPD to meet their daily goals and provides an instant reward, but the question remains whether this effect fades away with time. Unfortunately longterm follow-up outcomes have not yet been reported in literature.

One key to success in changing physical activity behaviour is to identify activities that patients truly love to perform. An Austrian trial on the effect of a 3-month Nordic walking programme reported that increased physical activity levels were sustained 6 months after the end of the trial [29]. Interestingly, over $60 \%$ of the patients adopted Nordic walking as a hobby. In line with this, a Spanish trial showed that patients who were offered access to a series of 32 local urban walking circuits (including information on public transport and cultural and commercial places of interest on the road; with varying difficulty and length) after finalising a short pulmonary rehabilitation programme increased physical activity levels up to 9 months after the end of the programme [82]. The latter strategy fits with current approaches to integrate health-promoting physical activity in daily routines. This is also termed active mobility, namely walking and cycling for transport solely or in combination with public transport [83]. Active mobility is economically affordable for most people, and provides an equitable and accessible form of physical activity. As such, it has the potential to reach population groups that are unresponsive to appeals and benefits of leisure time physical activity. Several studies already demonstrate the net health benefit of active mobility [84].

Even after successful behaviour change, patients might experience a relapse. Acute exacerbations of the disease are important reasons for prolonged inactivity [85]. Patients frequently identify exacerbations of the disease as an important barrier to exercise [75]. Unfortunately, a recent trial investigating the effectiveness of a physical activity counselling programme initiated during hospitalisation for an exacerbation failed to enhance physical activity levels in comparison to natural recovery [86]. Nevertheless, as exacerbations are key events in light of relapse within the behaviour-change process, they might be important moments for adequate monitoring and support in terms of physical activity behaviour by health professionals.

So, an increase in (outdoor) daily physical activity is expected to have a health benefit in patients with COPD [74]. However, outdoor exercise and active mobility may be associated not only with health benefits, but also with certain health risks in an urban environment. Indeed, the higher minute ventilation during physical activity, greater deposition fraction, a greater total particle deposition over the course of an exercise bout and oral breathing could all increase the dose (the amount deposited and retained in the body) of traffic-related air pollutants [87]. Air pollution is a heterogeneous mixture of compounds in gaseous (e.g. ozone, carbon monoxide, sulfur dioxide, nitrogen oxides), liquid and solid phases that can cause harm. Besides ozone, particulate matter (PM) appears to be the most widespread and harmful of air pollutants. PM is an air-suspended mixture of solid and liquid particles that vary in origin, chemical composition and physical properties [88]. PM is subdivided into categories based on the particle's aerodynamic diameter (particles <10 $\mu \mathrm{m}$ (PM10; the thoracic particles, i.e. those capable of passing beyond the larynx during inhalation); particles $<2.5 \mu \mathrm{m}$ (PM2.5; fine particles) and particles $<0.1 \mu \mathrm{m}$, the ultrafine particles (UFP). A large amount of research has demonstrated harmful effects of short- and longterm PM exposure on the respiratory and cardiovascular system, even at low PM levels. It is now well established that inhalation of PM induces adverse cardiovascular and pulmonary events, which underlie increased morbidity and mortality rates [89].

The issue of potential harmful health effects of air pollution has received ample media attention in the past during several Olympic Games, for which there was a major concern for the health and performance of competing athletes 


\section{Educational questions}

1 Exercise tolerance improves following exercise-based rehabilitation in patients with COPD due to:

a An increased motivation

b Desensitisation to dyspnoea

c True physiological changes at the level of the lower-limb muscles

$\mathrm{d}$ A combination of $\mathrm{a}, \mathrm{b}$ and $\mathrm{c}$

2 Which statement about exercise training in patients with COPD is true:

a Exercise training improves resting lung function in patients with COPD

b Exercise training can induce significant improvements in exercise performance and health status in comorbid COPD patients

c Exercise training has no positive effect on comorbidities in patients with COPD

$\mathrm{d}$ Exercise training is defined as any bodily movement produced by skeletal muscles that results in energy expenditure

3 Which statement about pulmonary rehabilitation in patients with COPD is true:

a Occupational therapy is the cornerstone of pulmonary rehabilitation

b Dietary counselling is the cornerstone of pulmonary rehabilitation

c Supervised exercise training is the cornerstone of pulmonary rehabilitation

d Psychosocial counselling is the cornerstone of pulmonary rehabilitation

4 What is true about physical activity:

a Lower physical activity hardly occurs in patients with COPD

b Physical activity is defined as planned, structured, and repetitive activities and has as a final or an intermediate objective the improvement or maintenance of physical fitness

c Direct feedback from a pedometer or an activity monitor seems to be an important tool to optimise the success rate of physical activity counselling programmes

d Six months of Nordic walking decrease physical activity levels in patients with COPD firm conclusions on this matter [101]. Altered cardiac autonomic function, changes in vascular function, oxidative stress and inflammation are potential pathophysiological pathways through which particulate air pollution can influence its effects [102-104]. Exercise and air pollution impinge on the same physiological mechanisms and health outcomes. Arterial compliance, exercise-induced hypotension and exercise-induced bronchodilatation may offset the effects of air pollution exposure. Regular physical exercise lowers the risk of heart disease and stroke, but these outcomes may be adversely affected by air pollution exposure. In this respect, there have been a series of impact assessments to estimate the population health implications of exercising in air pollution and they suggest that the beneficial effects of exercise outweigh the adverse effects of air pollution and that exercise offsets the adverse impacts of air pollution-related mortality and morbidity [105-108]. The studies were, however, not designed to look at disease onset or disease symptoms, especially in vulnerable groups such as COPD patients, and the data are far from comprehensive because they could not take into account confounding by exposure to pollutant mixtures containing varying concentrations of pollutants and different exercise protocols. More research is needed to unravel the complex interplay between lifestyle and environmental quality, but the current evidence supports that the risk-to-benefit ratio generally favours that every individual, including COPD patients, is encouraged to become more physically active and to perform regular aerobic exercise. Nevertheless, a greater effort should be made to educate patients and healthcare professionals about the risks of air pollutant exposures during exercise, particularly vulnerable groups [109]. Although no strategy has been directly tested to reduce morbidity and disease symptoms, several actions can be taken to lessen the degree of exposures during exercise, which may thereby help mitigate the adverse effects of air pollutants on exercise performance and possible health risk [110].

In summary, exercise training as part of a comprehensive pulmonary rehabilitation programme, can make a profound difference in the lives of patients with COPD. Indeed, exercise training reduces daily symptoms of dyspnoea and fatigue, improves physical fitness, reduces symptoms of anxiety/depression and improves quality of life in patients with COPD. Whether and to what extent an increase in (outdoor) daily physical activity will also improve these outcomes remains to be determined. 


\section{References}

1. Caspersen CJ, Powell KE, Christenson GM. Physical activity, exercise, and physical fitness: definitions and distinctions for health-related research. Public Health Rep 1985; 100: 126-131.

2. Ries AL, Bauldoff GS, Carlin BW, et al. Pulmonary rehabilitation: Joint ACCP/AACVPR Evidence-Based Clinical Practice Guidelines. Chest 2007; 131: 4S-42S.

3. Spruit MA, Singh SJ, Garvey C, et al. An official American Thoracic Society/European Respiratory Society statement: key concepts and advances in pulmonary rehabilitation. Am J Respir Crit Care Med 2013; 188: e13-e64.

4. en.wikipedia.org/wiki/International_Olympic_Committee. Date last accessed: April 26, 2016.

5. Denison C. Exercise and food for pulmonary invalids. Denver, The Chain \& Hardy Co., 1895.

6. Barach AL, Bickerman HA, Beck G. Advances in the treatment of non-tuberculous pulmonary disease. Bull NYAcad Med 1952; 28: 353-384.

7. Noehren TH, Barach AL, Brantigan OC, et al. Pulmonary emphysema: prevention and care. Dis Chest 1964; 45: 492-502.

8. Petty TL, Nett LM, Finigan MM, et al. A comprehensive care program for chronic airway obstruction. Methods and preliminary evaluation of symptomatic and functional improvement. Ann Intern Med 1969; 70: 1109-1120.

9. Bass H, Whitcomb JF, Forman R. Exercise training: therapy for patients with chronic obstructive pulmonary disease. Chest 1970; 57: 116-121.

10. Pitta F, Troosters T, Probst VS, et al. Physical activity and hospitalization for exacerbation of COPD. Chest 2006; 129: 536-544.

11. Hodgkin JE, Farrell MJ, Gibson SR, et al. American Thoracic Society. Medical Section of the American Lung Association. Pulmonary rehabilitation. Am Rev Respir Dis 1981; 124: 663-666.

12. Donner CF, Howard P. Pulmonary rehabilitation in chronic obstructive pulmonary disease (COPD) with recommendations for its use. Report of the European Respiratory Society Rehabilitation and Chronic Care Scientific Group (S.E.P.C.R. Rehabilitation Working Group). Eur Respir J 1992; 5: 266-275.

13. Pulmonary rehabilitation-1999. American Thoracic Society. Am J Respir Crit Care Med 1999; 159: 1666-1682.

14. Nici L, Donner C, Wouters E, et al. American thoracic society/European Respiratory Society statement on pulmonary rehabilitation. Am J Respir Crit Care Med 2006; 173: 1390-1413.

15. Belman MJ, Kendregan BA. Exercise training fails to increase skeletal muscle enzymes in patients with chronic obstructive pulmonary disease. Am Rev Respir Dis 1981; 123: 256-261.

16. Haber $P$. Exercise training fails to increase skeletal muscle enzymes in patients with chronic obstructive pulmonary disease - comment. Am Rev Respir Dis 1981; 124: 347-348.

17. Casaburi R, Patessio A, loli F, et al. Reductions in exercise lactic acidosis and ventilation as a result of exercise training in patients with obstructive lung disease. Am Rev Respir Dis 1991; 143: 9-18.

18. Maltais F, LeBlanc P, Simard C, et al. Skeletal muscle adaptation to endurance training in patients with chronic obstructive pulmonary disease. Am J Respir Crit Care Med 1996; 154: 442-447.

19. Ries AL, Kaplan RM, Limberg TM, et al. Effects of pulmonary rehabilitation on physiologic and psychosocial outcomes in patients with chronic obstructive pulmonary disease. Ann Intern Med 1995; 122: 823-832.

20. Maltais F, LeBlanc P, Jobin J, et al. Intensity of training and physiologic adaptation in patients with chronic obstructive pulmonary disease. Am J Respir Crit Care Med 1997; 155: 555-561.

21. Coppoolse R, Schols AM, Baarends EM, et al. Interval versus continuous training in patients with severe COPD: a randomized clinical trial. Eur Respir J 1999; 14: 258-263.
22. Simpson K, Killian K, McCartney N, et al. Randomised controlled trial of weightlifting exercise in patients with chronic airflow limitation. Thorax 1992; 47: 70-75.

23. O'Shea SD, Taylor NF, Paratz JD. Progressive resistance exercise improves muscle strength and may improve elements of performance of daily activities for people with COPD: a systematic review. Chest 2009; 136: 1269-1283.

24. Probst VS, Troosters T, Pitta F, et al. Cardiopulmonary stress during exercise training in patients with COPD. Eur RespirJ 2006; 27: 1110-1118.

25. Neder JA, Sword D, Ward SA, et al. Home based neuromuscular electrical stimulation as a new rehabilitative strategy for severely disabled patients with chronic obstructive pulmonary disease (COPD). Thorax 2002; 57: 333-337.

26. Wadell K, Sundelin G, Henriksson-Larsen K, et al. High intensity physical group training in water-an effective training modality for patients with COPD. Respir Med 2004; 98: 428-438

27. Dolmage TE, Goldstein RS. Response to one-legged cycling in patients with COPD. Chest 2006; 129: 325-332.

28. Chan AW, Lee A, Suen LK, et al. Effectiveness of a Tai chi Qigong program in promoting health-related quality of life and perceived social support in chronic obstructive pulmonary disease clients. Qual Life Res 2010; 19: 653-664.

29. Breyer MK, Breyer-Kohansal R, Funk GC, et al. Nordic walking improves daily physical activities in COPD: a randomised controlled trial. Respir Res 2010; 11: 112.

30. Gloeckl R, Heinzelmann I, Baeuerle S, et al. Effects of whole body vibration in patients with chronic obstructive pulmonary disease-a randomized controlled trial. Respir Med 2012; 106: 75-83.

31. Klijn P, van Keimpema A, Legemaat $M$, et al. Nonlinear exercise training in advanced COPD is superior to traditional exercise training: a randomized trial. Am J Respir Crit Care Med 2013.

32. Vogiatzis I, Nanas S, Roussos C. Interval training as an alternative modality to continuous exercise in patients with COPD. Eur Respir J 2002; 20: 12-19.

33. Weston KS, Wisloff U, Coombes JS. High-intensity interval training in patients with lifestyle-induced cardiometabolic disease: a systematic review and meta-analysis. BrJ Sports Med 2014; 48: 1227-1234.

34. Vogiatzis I, De Vito G. Physiological assessment of Olympic windsurfers. Eur J Sport Sci 2015; 15: 228-234.

35. Castagna O, Brisswalter J, Lacour JR, et al. Physiological demands of different sailing techniques of the new Olympic windsurfing class. Eur J Appl Physiol 2008; 104: 1061-1067.

36. Vogiatzis I, De Vito G, Rodio A, et al. The physiological demands of sail pumping in Olympic level windsurfers. Eur J Appl Physiol 2002; 86: 450-454.

37. Vogiatzis I, Nanas S, Kastanakis E, et al. Dynamic hyperinflation and tolerance to interval exercise in patients with advanced COPD. Eur Respir J 2004; 24: 385-390.

38. Vogiatzis I, Terzis G, Nanas S, et al. Skeletal muscle adaptations to interval training in patients with advanced COPD. Chest 2005; 128: 3838-3845.

39. Georgiadou O, Vogiatzis I, Stratakos G, et al. Effects of rehabilitation on chest wall volume regulation during exercise in COPD patients. Eur Respir J 2007; 29: 284-291.

40. Nasis I, Kortianou E, Vasilopoulou M, et al. Hemodynamic effects of high intensity interval training in COPD patients exhibiting exercise-induced dynamic hyperinflation. Respir Physiol Neurobiol 2015; 217: 8-16.

41. Vestbo J, Hurd SS, Agusti AG, et al. Global Strategy for the Diagnosis, Management, and Prevention of Chronic Obstructive Pulmonary Disease: GOLD Executive Summary. Am J Respir Crit Care Med 2013; 187: 347-365.

42. Mannino DM, Thorn D, Swensen A, et al. Prevalence and outcomes of diabetes, hypertension and cardiovascular disease in COPD. Eur Respir J 2008; 32: 962-969.

\section{Suggested Answers}

\author{
1. $d$ \\ 2. $b$ \\ 3. c \\ 4. C
}


43. Divo M, Cote C, Torres JP, et al. Comorbidities and risk of mortality in patients with chronic obstructive pulmonary disease. Am J Respir Crit Care Med 2012; 186 155-161.

44. Miller J, Edwards LD, Agusti A, et al. Comorbidity, sys temic inflammation and outcomes in the ECLIPSE cohort. Respir Med 2013; 107: 1376-1384.

45. Decramer M, Rennard S, Troosters T, et al. COPD as a lung disease with systemic consequences-clinical impact mechanisms, and potential for early intervention. COPD 2008; 5: 235-256.

46. Vanfleteren LE, Spruit MA, Groenen M, et al. Clusters of comorbidities based on validated objective measurements and systemic inflammation in patients with chronic obstructive pulmonary disease. Am J Respir Crit Care Med 2013; 187: 728-735.

47. Franssen FM, Rochester CL. Comorbidities in patients with COPD and pulmonary rehabilitation: do they matter? Eur Respir Rev 2014; 23: 131-141.

48. Triest FJ, Franssen FM, Spruit MA, et al. Poor agreement between chart-based and objectively identified comorbidities of COPD. Eur Respir J 2015; 46: 1492-1495.

49. Crisafulli E, Gorgone P, Vagaggini B, et al. Efficacy of standard rehabilitation in COPD outpatients with comorbidities. Eur Respir J 2010; 36: 1042-1048.

50. Mesquita R, Vanfleteren LE, Franssen FM, et al. Objectively identified comorbidities in chronic obstructive pulmonary disease: impact on pulmonary rehabilitation outcomes. Eur Respir J 2015

51. Spruit MA, Singh SJ, Garvey C, et al. An Official American Thoracic Society/European Respiratory Society Statement: Key concepts and advances in pulmonary rehabilitation. Am J Respir Crit Care Med 2013.

52. Coventry PA, Hind D. Comprehensive pulmonary rehabilitation for anxiety and depression in adults with chronic obstructive pulmonary disease: Systematic review and meta-analysis. J Psychosom Res 2007; 63: 551-565.

53. Gale NS, Duckers JM, Enright S, et al. Does pulmonary rehabilitation address cardiovascular risk factors in patients with COPD? BMC Pulm Med 2011; 11: 20.

54. Vivodtzev I, Minet C, Wuyam B, et al. Significant improvement in arterial stiffness after endurance training in patients with COPD. Chest 2010; 137: 585-592.

55. Vanfleteren LE, Spruit MA, Groenen MT, et al. Arterial stiffness in patients with COPD: the role of systemic inflammation and the effects of pulmonary rehabilitation. Eur Respir J 2014; 43: 1306-1315.

56. Schols AM, Ferreira IM, Franssen FM, et al. Nutritional assessment and therapy in COPD: a European Respiratory Society statement. Eur Respir J 2014; 44: 1504-1520.

57. McDonald VM, Gibson PG, Scott HA, et al. Should we treat obesity in COPD? The effects of diet and resistance exercise training. Respirology 2016; in press [DOI: 10.1111/resp. 12746].

58. McCarthy B, Casey D, Devane D, et al. Pulmonary rehabilitation for chronic obstructive pulmonary disease. Cochrane Database Syst Rev 2015; 2: CD003793.

59. Spruit MA, Pitta F, Garvey C, et al. Differences in content and organisational aspects of pulmonary rehabilitation programmes. Eur Respir J 2014; 43: 1326-1337

60. Hill K, Vogiatzis I, Burtin C. The importance of components of pulmonary rehabilitation, other than exercise training, in COPD. Eur Respir Rev 2013; 22: 405-413.

61. Augustin IM, Spruit MA, Franssen FME, et al. Understanding complexity of chronic non-communicable diseases: an integrated approach for personalized management of patients with COPD. Clin Res Pulmonol 2015 3: 1034.

62. Vaes AW, Meijer K, Delbressine JM, et al. Efficacy of walking aids on self-paced outdoor walking in individuals with COPD: A randomized cross-over trial. Respirology 2015; 20: 932-939.

63. Vaes AW, Annegarn J, Meijer K, et al. The effects of a "new" walking aid on exercise performance in patients with COPD: a randomized crossover trial. Chest 2012; 141 1224-1232.
64. Gosselink R. Controlled breathing and dyspnea in patients with chronic obstructive pulmonary disease (COPD). J Rehabil Res Dev 2003; 40: 25-33.

65. Schols AM, Ferreira IM, Franssen FM, et al. Nutritional assessment and therapy in COPD: a European Respiratory Society statement. Eur Respir J 2014; 44: 1504-1520

66. Vorrink SN, Kort HS, Troosters T, et al. Level of daily physical activity in individuals with COPD compared with healthy controls. Respir Res 2011; 12: 33.

67. Watz H, Pitta F, Rochester CL, et al. An official European Respiratory Society statement on physical activity in COPD. Eur Respir J 2014; 44: 1521-1537.

68. Garcia-Aymerich J, Lange P, Benet $M$, et al. Regular physical activity reduces hospital admission and mortality in chronic obstructive pulmonary disease: a population based cohort study. Thorax 2006; 61: 772-778.

69. Sievi NA, Franzen D, Kohler M, et al. Physical inactivity and arterial stiffness in COPD. Int J Chron Obstruct Pulmon Dis 2015; 10: 1891-1897.

70. Garcia-Aymerich J, Lange P, Benet $M$, et al. Regular physical activity modifies smoking-related lung function decline and reduces risk of chronic obstructive pulmonary disease: a population-based cohort study. Am J Respir Crit Care Med 2007; 175: 458-463.

71. Vaes AW, Garcia-Aymerich J, Marott JL, et al. Changes in physical activity and all-cause mortality in COPD. Eur Respir J 2014; 44: 1199-1209.

72. Esteban C, Arostegui I, Aburto M, et al. Influence of changes in physical activity on frequency of hospitalization in chronic obstructive pulmonary disease. Respirology 2014; 19: 330-338.

73. Cindy Ng LW, Mackney J, Jenkins S, et al. Does exercise training change physical activity in people with COPD? A systematic review and meta-analysis. Chron Respir Dis 2012; 9: 17-26.

74. Spruit MA, Pitta F, McAuley E, et al. Pulmonary rehabilitation and physical activity in patients with chronic obstructive pulmonary disease. Am J Respir Crit Care Med 2015; 192: 924-933.

75. Thorpe O, Johnston K, Kumar S. Barriers and enablers to physical activity participation in patients with COPD: a systematic review. J Cardiopulm Rehabil Prev 2012; 32: 359-369.

76. Soicher JE, Mayo NE, Gauvin L, et al. Trajectories of endurance activity following pulmonary rehabilitation in COPD patients. Eur Respir J 2012; 39: 272-278.

77. Burtin C, Langer D, Remoortel $\mathrm{H}$, et al. Physical activity counselling during pulmonary rehabilitation in patients with COPD: a randomised controlled trial. PLoS One 2015 10: e0144989.

78. Bravata DM, Smith-Spangler C, Sundaram V, et al. Using pedometers to increase physical activity and improve health: a systematic review. JAMA 2007; 298: 2296-2304.

79. Altenburg WA, Hacken $\mathrm{NH}$, Bossenbroek L, et al. Short- and long-term effects of a physical activity counselling programme in COPD: a randomized controlled trial. Respir Med 2015; 109: 112-121.

80. Moy ML, Collins RJ, Martinez CH, et al. An internet-mediated pedometer-based program improves health-related quality-of-life domains and daily step counts in COPD: a randomized controlled trial. Chest 2015; 148: 128-137.

81. Vorrink SN, Kort HS, Troosters T, et al. A mobile phone app to stimulate daily physical activity in patients with chronic obstructive pulmonary disease: development, feasibility, and pilot studies. JMIR Mhealth Uhealth 2016; 4: e11.

82. Pleguezuelos E, Perez ME, Guirao L, et al. Improving physical activity in patients with COPD with urban walking circuits. Respir Med 2013; 107: 1948-1956.

83. Gerike R, Nazelle A, Nieuwenhuijsen M, et al. Physical Activity through Sustainable Transport Approaches (PASTA): a study protocol for a multicentre project. BMJ Open 2016; 6: e009924. 
84. Mueller N, Rojas-Rueda D, Cole-Hunter T, et al. Health impact assessment of active transportation: a systematic review. Prev Med 2015; 76: 103-114

85. Pitta F, Troosters T, Probst VS, et al. Physical activity and hospitalization for exacerbation of COPD. Chest 2006; 129: $536-544$

86. Hornikx M, Demeyer H, Camillo CA, et al. The effects of a physical activity counseling program after an exacerbation in patients with Chronic Obstructive Pulmonary Disease: a randomized controlled pilot study. BMC Pulm Med 2015; 15: 136

87. Giles LV, Koehle MS. The health effects of exercising in air pollution. Sports Med 2014; 44: 223-249.

88. Pope CAIII, Dockery DW. Health effects of fine particulate air pollution: lines that connect. J Air Waste Manag Assoc 2006; 56: 709-742.

89. Brook RD, Rajagopalan S, Pope CA, et al. Particulate matter air pollution and cardiovascular disease: An update to the scientific statement from the American Heart Association. Circulation 2010; 121: 2331-2378.

90. Cutrufello PT, Smoliga JM, Rundell KW. Small things make a big difference: particulate matter and exercise. Sports Med 2012; 42: 1041-1058.

91. Florida-James G, Donaldson K, Stone V. Athens 2004: the pollution climate and athletic performance. J Sports Sci 2004; 22: 967-980.

92. Marr LC, Ely MR. Effect of air pollution on marathon running performance. Med Sci Sports Exerc 2010; 42: 585-591.

93. McCreanor J, Cullinan P, Nieuwenhuijsen MJ, et al. Respiratory effects of exposure to diesel traffic in persons with asthma. N EnglJ Med 2007; 357: 2348-2358.

94. Strak M, Boogaard H, Meliefste $K$, et al. Respiratory health effects of ultrafine and fine particle exposure in cyclists. Occup Environ Med 2010; 67: 118-124.

95. Chimenti L, Morici G, Paterno A, et al. Environmental conditions, air pollutants, and airway cells in runners: a longitudinal field study. J Sports Sci 2009; 27: 925-935.

96. Strak M, Hoek G, Godri KJ, et al. Composition of PM affects acute vascular inflammatory and coagulative markers - the RAPTES project. PLoS One 2013; 8: e58944.

97. Cutrufello PT, Rundell KW, Smoliga JM, et al. Inhaled whole exhaust and its effect on exercise performance and vascular function. Inhal Toxicol 2011; 23: 658-667.
98. Rundell KW. Effect of air pollution on athlete health and performance. BrJ Sports Med 2012; 46: 407-412.

99. Bos I, De B, Vanparijs J, et al. Subclinical effects of aerobic training in urban environment. Med Sci Sports Exerc 2013; 45: 439-447.

100. Bos I, Jacobs L, Nawrot TS, et al. No exercise-induced increase in serum BDNF after cycling near a major traffic road. Neurosci Lett 2011; 500: 129-132.

101. Cliff R, Curran J, Hirota JA, et al. Effect of diesel exhaust inhalation on blood markers of inflammation and neurotoxicity: a controlled, blinded crossover study. Inhal Toxicol 2016; 28: 145-153.

102. Brook RD, Rajagopalan S. Particulate matter air pollution and atherosclerosis. Curr Atheroscler Rep 2010; 12 : 291-300.

103. Franklin BA, Brook R, Arden Pope CIII. Air pollution and cardiovascular disease. Curr Probl Cardiol 2015; 40: 207-238.

104. Pieters N, Plusquin M, Cox B, et al. An epidemiological appraisal of the association between heart rate variability and particulate air pollution: a meta-analysis. Heart 2012; 98: 1127-1135.

105. Andersen ZJ, Nazelle A, Mendez MA, et al. A study of the combined effects of physical activity and air pollution on mortality in elderly urban residents: the Danish Diet, Cancer, and Health Cohort. Environ Health Perspect 2015; 123: 557-563

106. Johan de Hartog J, Boogaard H, Nijland H, et al. Do the health benefits of cycling outweigh the risks? Environ Health Perspect 2010; 118: 1109-1116.

107. Rojas-Rueda D, de Nazelle A, Tainio M, et al. The health risks and benefits of cycling in urban environments compared with car use: health impact assessment study. BMJ 2011; 343: d4521.

108. Woodcock J, Tainio M, Cheshire J, et al. Health effects of the London bicycle sharing system: health impact modelling study. BMJ 2014; 348: g425.

109. Giorgini P, Rubenfire M, Bard RL, et al. Air pollution and exercise: a review of the cardiovascular implications for health care professionals. J Cardiopulm Rehabil Prev 2016; 36: 84-95.

110. Exercise and air quality: 10 top tips. Breathe 2015; 11: $239-242$. 